\title{
Estimation of Ion Beam Trajectories for a Slot Aperture Accelerator of Long-Pulse Ion Source in Neutral Beam Injector
}

\author{
Doo-Hee Chang \\ Nuclear Fusion Engineering \& Technology Development Center, Korea Atomic Energy Research Institute, \\ Daejeon, Republic of Korea \\ Email: doochang@kaeri.re.kr
}

Received February 1, 2013; revised March 4, 2013; accepted March 12, 2013

Copyright (C) 2013 Doo-Hee Chang. This is an open access article distributed under the Creative Commons Attribution License, which permits unrestricted use, distribution, and reproduction in any medium, provided the original work is properly cited.

\begin{abstract}
A neutral beam injection (NBI) system has been developed and is being tested for an Experimental Advanced Superconducting Tokamak (EAST) device. The NBI system needs to be employed for an auxiliary heating and current drive of EAST plasmas. The first long pulse ion source (LPIS-1) has been installed in the neutral beam test bed (NBTB) system, and the performance is being tested in the NBTB. The LPIS-1 consists of a magnetic bucket plasma generator with multipole cusp-fields and a set of tetrode accelerators with slit-type apertures (a transparency of $60 \%$ ). The ion beam trajectories of the accelerator column are estimated for the LPIS-1, including an original structure, with the change of slit aperture distance, plasma grid shape, grid gap distance, and voltage ratio between a plasma grid and a gradient grid using the IGUN code. This kind of calculation for the ion beam trajectory may be useful for the estimation of beam extraction characteristics and the direction of accelerator upgrade or modification, prior to the experiments of ion beam extraction.
\end{abstract}

Keywords: Long Pulse Ion Source; Slot Aperture Accelerator; EAST; Neutral Beam Injection; Ion Beam Trajectory; IGUN Code

\section{Introduction}

A neutral beam injection (NBI) system is essential for next-generation fusion research devices, such as the International Thermonuclear Experimental Reactor (ITER), as an auxiliary heating and current drive because of the high performance required for long-pulse or continuous steady-state burning-experiments [1,2]. Worldwide, large tokamaks such as JET (EU), TFTR (USA), DIII-D (USA), JT-60U (Japan), and KSTAR (Korea) have used the NBI system for high-performance operation during the last few ten years and the recent operations [3-7]. The first NBI system has been developed for the Experimental Advanced Superconducting Tokamak (EAST) device [8, 9]. The first long pulse ion source (LPIS-1) was developed for the EAST NBI system, and the arc discharges of the ion source were characterized for the EAST NB injector [10-12]. The design requirements of the LPIS-1 for the EAST NBI system were a $80 \mathrm{kV} / 70 \mathrm{~A}$ deuterium ion beam and a 100 s beam pulse length [12], and the nominal operation requirements for the ion source (IS) were a 50 -
$80 \mathrm{kV} / 40$ - 70 A deuterium beam and a 10 - 100-second pulse length [11]. The beamline components (BLCs) of NBI were developed initially for a total neutral beam power of $4 \mathrm{MW}$ at $80 \mathrm{kV}$, originating from the deuterium ion beams and injected into the core plasmas of the EAST, with two LPISs in one beamline. The final destination of the EAST NBI system aims at the injection of a deuterium beam power of more than $8 \mathrm{MW}$ at a beam energy of $80 \mathrm{keV}$ through two beam lines. According to the planned role of the NB injector, the NBI system will be operated for beam injection into the EAST plasmas from the 2014 EAST campaign, including the system commissioning of each component and sub-system in the NB test bed (NBTB) [12].

The first LPIS (LPIS-1) is composed of a plasma generator and a set of prototype tetrode accelerators. The plasma generator and beam accelerator, called a US common long pulse ion source (US CLPIS), were originally developed by General Atomics (GA) in USA [13, 14]. The LPIS-1 consists of a magnetic bucket plasma 
generator with multi-pole cusp fields, and a set of tetrode accelerators with molybdenum slit apertures. The LPIS-1 has an overall beam extraction area of $12 \times 48 \mathrm{~cm}^{2}$ with linear water-cooling channels along the short dimension of every slit aperture array. The transparency of an accelerator column in the ion source is $60 \%$ with 55 slot apertures with a $5.4 \mathrm{~mm}$ slot distance. The BLCs of the NBTB system include a neutralizer, a bending magnet (BM), an ion dump (ID), a fixed calorimeter, and a cryocondensation pump system in a vacuum enclosure (a cylindrical shape with a radius of $1.75 \mathrm{~m}$ and a length of $4 \mathrm{~m}$ ) [8,9]. A beam duct will be connected between the NB vacuum enclosure and the vacuum vessel of the EAST device. The BLCs of the NBI system have been designed for the installation of two ion sources in one beamline. All data and parameters of the NBTB system were controlled by a control and data acquisition (CODAQ) system through PC-based monitoring, control, and interlock systems based on an Ethernet interface.

The ion beam trajectories of the accelerator column are estimated for the LPIS-1, including an original structure, with the change of slit aperture distance, plasma grid shape, grid gap distance, and voltage ratio between a plasma grid and a gradient grid using the IGUN code [15]. The IGUN numerical simulation has been extensively utilized for the design iteration. From the IGUN simulation, divergence information and emittance information are obtained as well as ion orbits. Ion optics of various geometries were studied theoretically and experimentally by means of an analytic linear optics analysis and a numerical simulation using the IGUN program $[16,17]$. In general, there was a reasonable agreement observed between the theoretical predictions and the experimental measurements. The deviation of the experimental divergence angles from the IGUN can be explained by the fact that the multi-aperture system produces other effects that make the beam optics worse. Furthermore, the difference in the optimum beam perveance (perv $\equiv \mathrm{A} / \mathrm{V}^{3 / 2} \times 10^{-6}, \mathrm{~A}$ : beam current $[\mathrm{A}], \mathrm{V}$ : applied beam voltage [V]) between the numerical calculation and experimental results must be caused mainly by the accelerator structures and the effective ion mass. However, this kind of calculation for the ion beam trajectory may be useful for the estimation of beam extraction characteristics and the direction of accelerator modification, prior to the experiments of the ion beam extraction.

\section{Simulation Methods for Optics Analysis}

Divergence angles and an optimum beam perveance with the different accelerator structures and aperture shapes are obtained for the slot grid accelerator using the calculation of IGUN program. IGUN is a PC-based program for the simulation of positive ion extraction from the plasmas [16]. The mathematical simulation of plasma sheath is based on a simple analytical model, which provides a numerically stable calculation of sheath potential. IGUN is able to determine the extracted ion current in succeeding cycles of iteration. IGUN is also possible to set values of current, plasma density, or ion current density. Either axisymmetric or rectangular coordinates can be used, including axisymmetric or transverse magnetic fields.

The accelerator of LPIS-1 consists of a set of tetrode accelerators, including a plasma grid (G1), a gradient grid (G2), a suppressor grid (G3), and a ground grid (G4), for dual-stage beam extraction through the slit apertures. A conceptual drawing and symbols of the accelerator column in the LPIS-1 for the beam extractions are shown in Figure 1. The slit-aperture tetrode column is defined in the figure. The first grid G1 defines the source plasma, from which ions are extracted. The first gap extracts ions from the G1 apertures and the second gap post-accelerates the ion beam to a desired level. The third gap is used to suppress the electrons of the gas-cell neutralizer plasma from beams back-accelerated. The final grid G4 is a reference electrode connected directly to the ground potential during the beam extraction.

For the calculation of the IGUN code, five variations of the accelerator structure are estimated for the LPIS-1. The dimensions of the five variations for the accelerator structure are specified in Table 1. The voltage ratios between $\mathrm{G} 1$ and $\mathrm{G} 2$ are varied with $80 \%, 83 \%$, and $86 \%$ for the calculation of every structure. A G1 voltage of 80 $\mathrm{kV}$ and $\mathrm{G} 3$ voltage of $-3.0 \mathrm{kV}$ are used for this simulation. Type- 1 has the same structure as the present LPIS-1 in the NBTB system. For Type-2, the slot distance between G1 and G2 is reversed. This means that the slot distance of the plasma grid is longer than the gradient grid. For Type-3, the grid shape of G1 is a rhombic one, which is the same structure as the original US CLPIS, even though the grid thickness is slightly lower than the present circular shape in the LPIS-1. The first gap distance between G1 and G2 is only reduced to $3.5 \mathrm{~mm}$ from $4.5 \mathrm{~mm}$ in Type-4. The first gap (between G1 and G2) and the second gap (between G2 and G3) are reduced to $3.5 \mathrm{~mm}$ and $9.0 \mathrm{~mm}$ from $4.5 \mathrm{~mm}$ and $11.0 \mathrm{~mm}$, respectively, in Type-5.

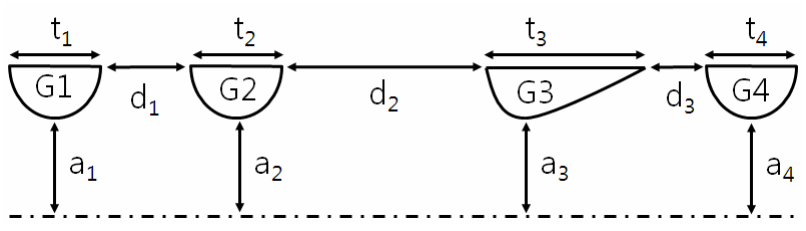

Figure 1. Conceptual drawing and symbols of accelerator column for the LPIS-1 of EAST NBI system. 
Table 1. Dimension of the five variations for the accelerator structure.

\begin{tabular}{cccccccccccc}
\hline Type & $\mathrm{a}_{1}$ & $\mathrm{a}_{2}$ & $\mathrm{a}_{3}$ & $\mathrm{a}_{4}$ & $\mathrm{t}_{1}$ & $\mathrm{t}_{2}$ & $\mathrm{t}_{3}$ & $\mathrm{t}_{4}$ & $\mathrm{~d}_{1}$ & $\mathrm{~d}_{2}$ & $\mathrm{~d}_{3}$ \\
\hline 1 (Present) & 2.7 & 2.9 & 2.2 & 2.9 & 3.6 & 3.2 & 6.0 & 3.2 & 4.5 & 11.0 & 2.5 \\
2 & 2.9 & 2.7 & 2.2 & 2.9 & 3.6 & 3.2 & 6.0 & 3.2 & 4.5 & 11.0 & 2.5 \\
3 (CLPIS) & 2.7 & 2.9 & 2.2 & 2.9 & 2.8 (Rhombus) & 3.2 & 6.0 & 3.2 & 4.5 & 11.0 & 2.5 \\
4 & 2.7 & 2.9 & 2.2 & 2.9 & 3.6 & 3.2 & 6.0 & 3.2 & 3.5 & 11.0 & 2.5 \\
5 & 2.7 & 2.9 & 2.2 & 2.9 & 3.6 & 3.2 & 6.0 & 3.2 & 3.5 & 9.0 & 2.5 \\
\hline
\end{tabular}

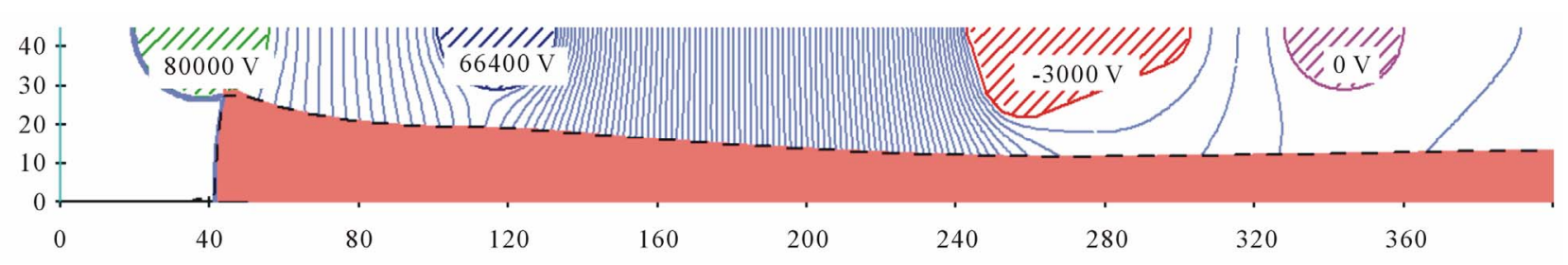

(a)

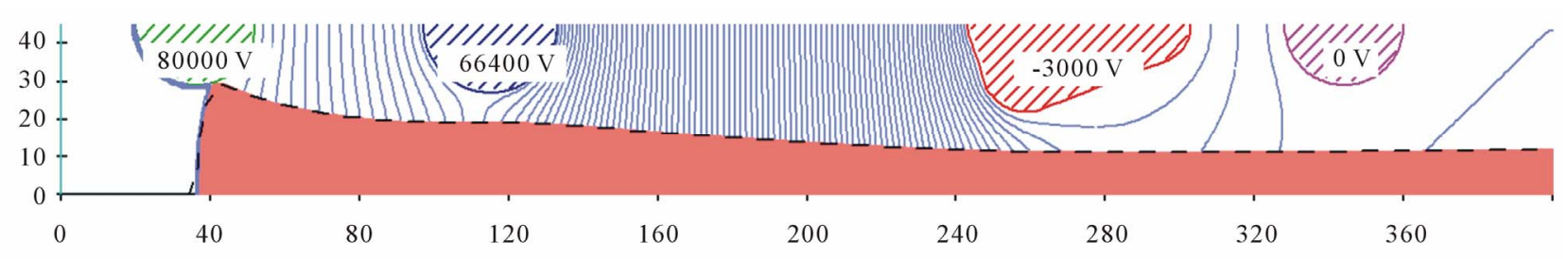

(b)

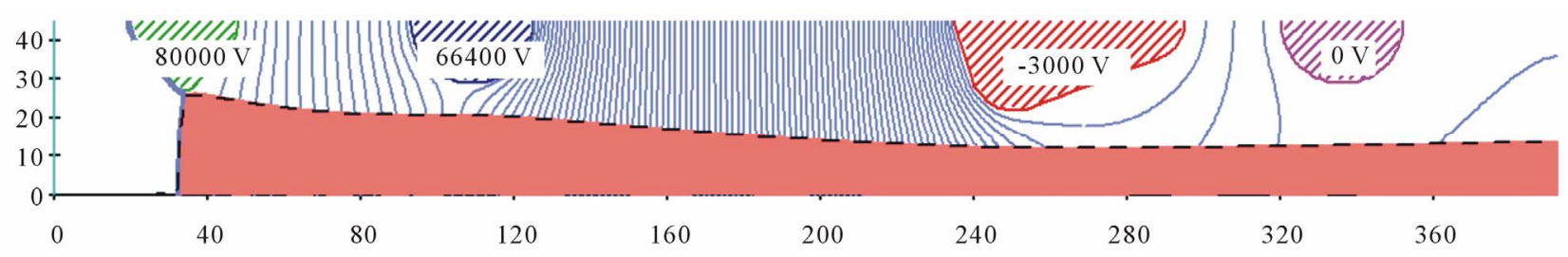

(c)

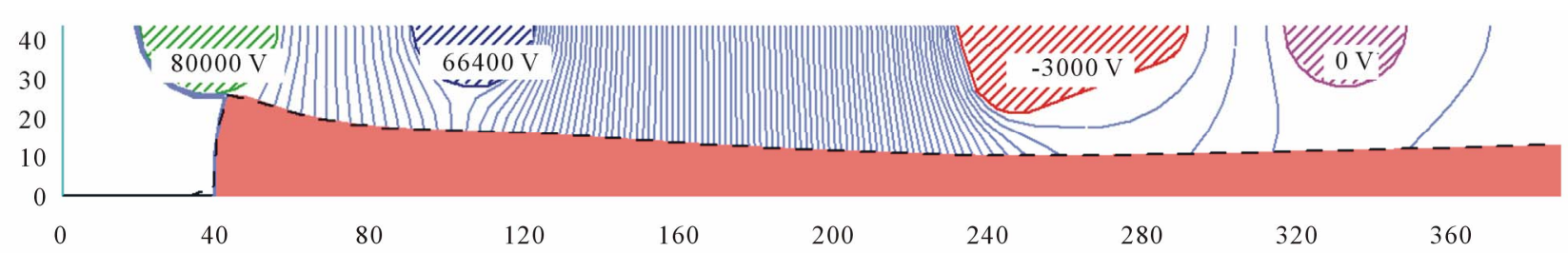

(d)

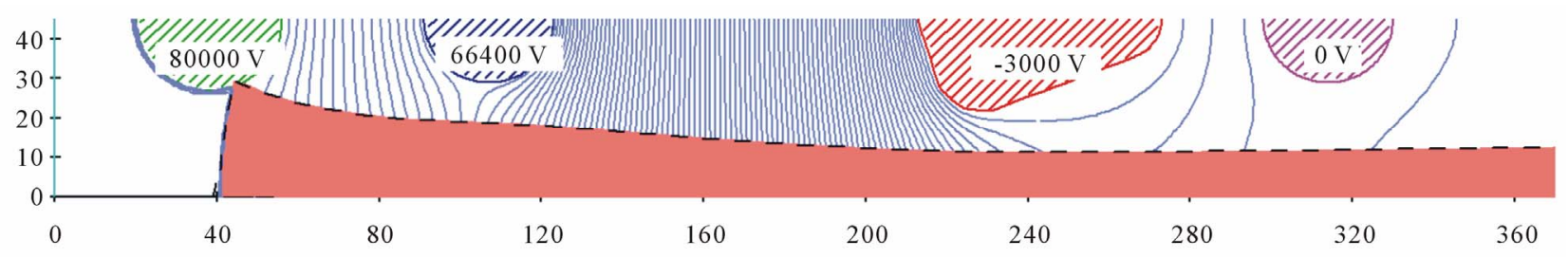

(e)

Figure 2. Examples of the calculation for ion beam trajectories with an ion mass of 2 (pure deuterium beam) by using IGUN code: (a) Type-1; (b) Type-2; (c) Type-3; (d)Type-4; (e) Type-5. 


\section{Simulation Results and Discussion}

Figure 2 shows an example of calculated ion beam trajectories near the optimum beam perveance, passing through the accelerator column of the five accelerator structures. The calculated RMS (root-mean-square)-divergence angle vs beam perveance for the five accelerator structures are shown in Figure 3. The perpendicular

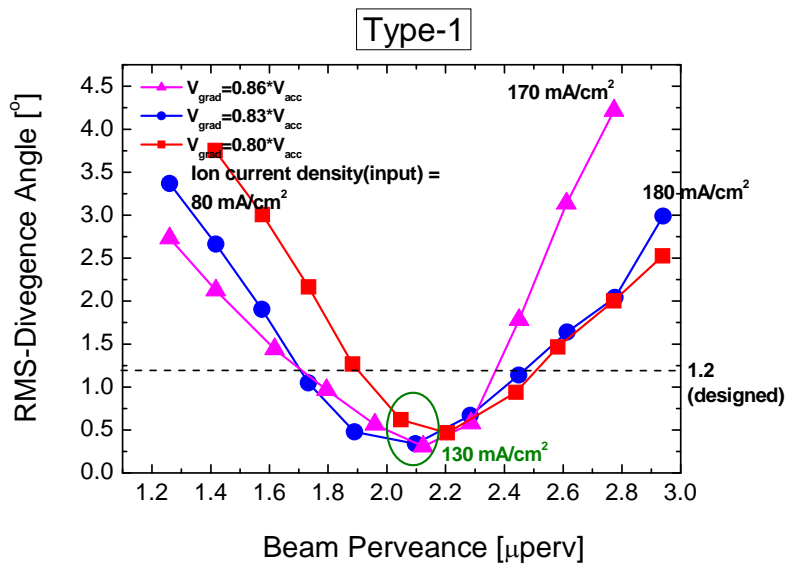

(a)

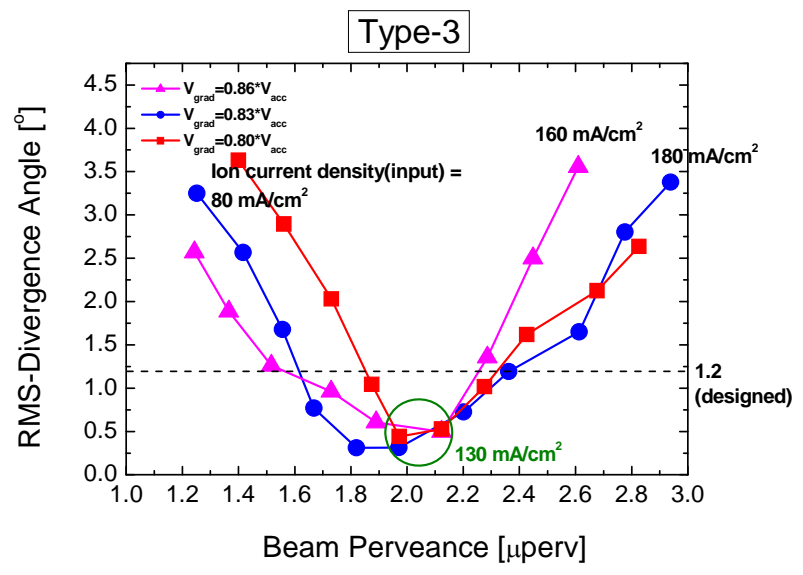

(c) divergence angle of LPIS-1 is acceptable up to 1.2 degrees based on the design requirement of the EAST NBI system. Optimum beam perveances of five accelerator structures are $\sim 2.1$ (Type-1), 2.0 (Type-2), 2.0 (Type3), 2.4 (Type-4), and 2.7 (Type-5) $\mu$ perv, respectively. The input values of the ion current density for the IGUN simulation are varied to within $80-230 \mathrm{~mA} / \mathrm{cm}^{2}$. It can

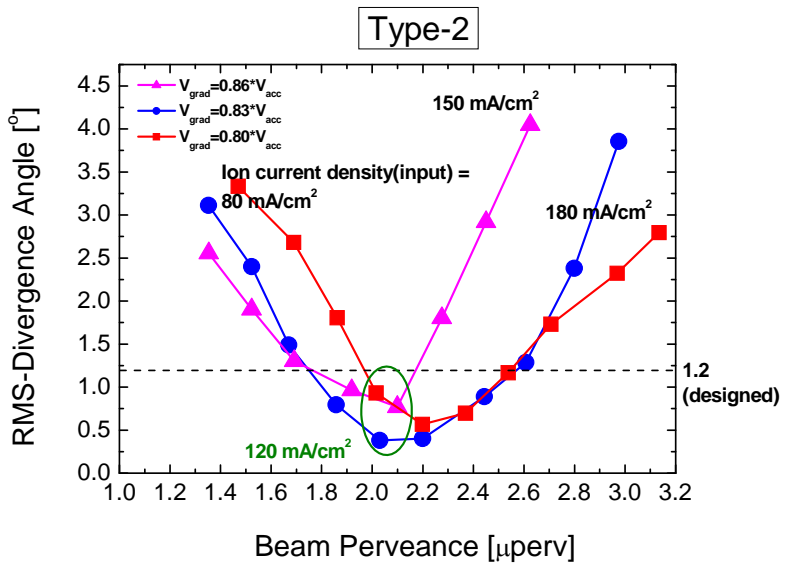

(b)

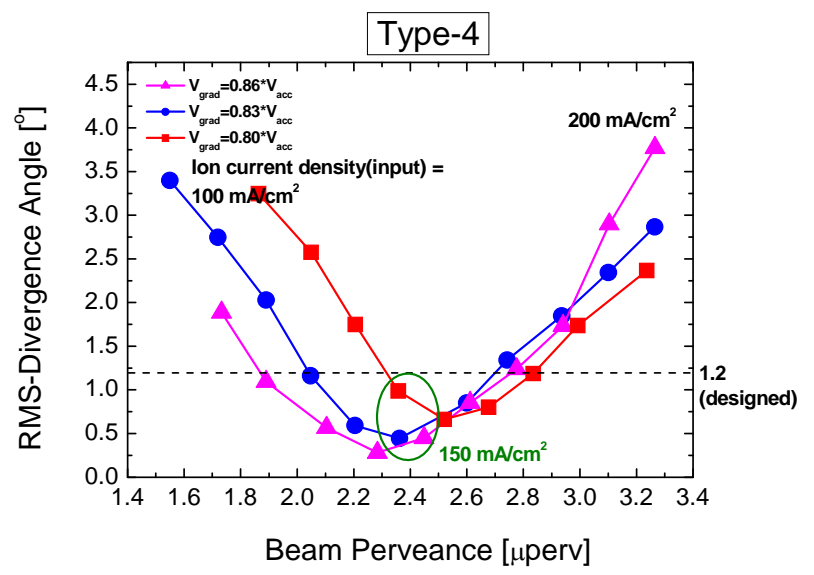

(d)

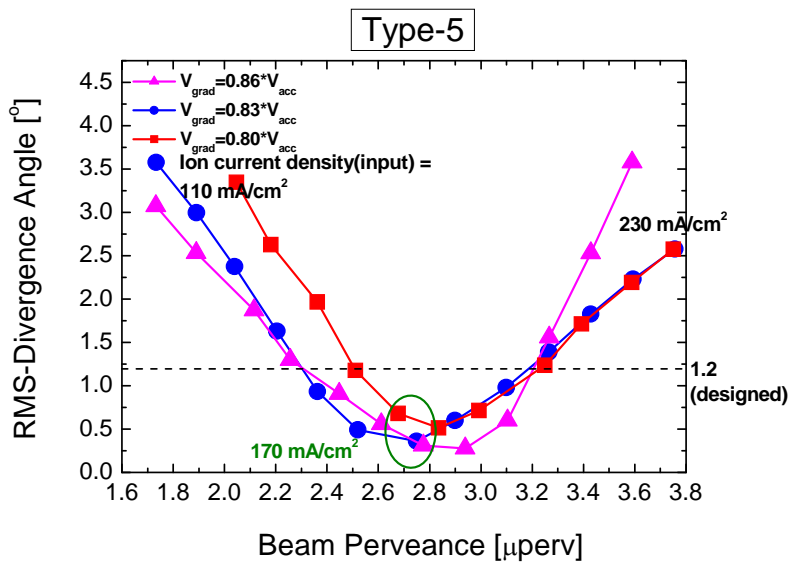

(e)

Figure 3. RMS-divergence angle of five accelerator structures: (a) Type-1; (b) Type-2; (c) Type-3; (d)Type-4; (e) Type-5. 
be found that an optimum beam perveance must be increased with an increase in the divergence angle when the voltage ratio between G1 and G2 is gradually decreased. On the other hand, an optimum beam pervenance is decreased with a decrease in divergence angle when the voltage ratio between G1 and G2 is increased. This implies that the voltage ratio between $\mathrm{G} 1$ and G2 should be decreased to increase the extractable beam current. However, the beam divergence angle must be increased in this situation. The big increase in the extractable beam current can be obtained with the reduction of the first and second gap distances. However, the capability of high voltage holding during the beam extraction process should be considered in the reduced gap distances. The heat load on the grid surface should always be considered whenever the applied voltage ratio and source plasma density (source ion density) are changed.

The experimental results of the Type- 1 and Type- 3 accelerators were reported for the DIII-D NBI ion source [18]. An optimum beam perveance of $\sim 2.7 \mu$ perv for Type-1 was observed experimentally by the measurement of G2 currents and the diagnostics of the optical spectrometry. An optimum beam perveance of Type- 3 was $\sim 2.8 \mu$ perv. For the LPIS-1 of EAST NBI system, it can be decided that the relationship of Type- 1 between the experimental and simulated results (using the IGUN code) is $\mathrm{P}_{\text {exp }}=\mathrm{CP}_{\text {cal }}$, where $\mathrm{P}_{\exp }$ is the experimental optimum perveance, $\mathrm{C}$ is the weight coefficient (1.29 for the LPIS-1) depending on the accelerator type, and $\mathrm{P}_{\mathrm{cal}}$ is the calculated beam perveance. The deviation of the experimental divergence angles from the IGUN can be explained by the fact that the multi-aperture system produces other critical effects that make the beam optics bad. In general, the beam optics depends severely on the accelerator structures, aperture shape, fabrication precision, aperture alignment, and effective ion mass.

\section{Conclusion}

The ion beam trajectories of the accelerator column in the LPIS-1 are estimated for the EAST NBI system with the change of slit aperture distance, plasma grid shape, grid gap distance, and voltage ratio between a plasma grid and a gradient grid using the IGUN code. The variation of voltage ratio between plasma grid (G1) and gradient grid (G2) affects the extractable beam current and beam divergence angle. A big increase in the extractable beam current can be obtained with a reduction of first and second gap distances in the accelerator column. The capability of high voltage holding during the beam extraction process should be considered in the reduction of the gap distances. The calculation of the ion beam trajectory may be useful for the estimation of beam extraction characteristics and the direction of accelerator modi- fication, prior to the experiments on ion beam extraction.

\section{Acknowledgements}

This work was supported by 2011 Korea-China Joint Research Program through the National Research Foundation of Korea (NRF) funded by Korean government funds. The authors are thankful for the great efforts of the research staff at the Korea Atomic Energy Research Institute (KAERI) in Korea and the Institute of Plasma Physics, Chinese Academy of Science (ASIPP) in China.

\section{REFERENCES}

[1] R. Hemsworth, H. Decamps, J. Graceffa, B. Schunke, M. Tanaka, M. Dremel, A. Tanga, H. P. L. De Esch, F. Geli, J. Milnes, T. Inoue, D. Marcuzzi, P. Sonato and P. Zaccaria, "Status of the ITER Heating Neutral Beam System," Nuclear Fusion, Vol. 49, No. 4, 2009, Article ID: 045006.

[2] L. R. Grisham, P. Agostinetti, G. Barrera, P. Blatchford, D. Boilson, J. Chareyre, G. Chitarin, H. P. L. de Esch, A. De Lorenzi, P. Franzen, U. Fantz, M. Gagliardi, R. S. Hemsworth, M. Kashiwagi, D. King, A. Krylov, M. Kuriyama, N. Marconato, D. Marcuzzi, M. Roccella, L. Rios, A. Panasenkov, N. Pilan, M. Pavei, A. Rizzolo, E. Sartori, G. Serianni, P. Sonato, V. Pilard, M. Tanaka, H. Tobari, P. Veltri and P. Zaccari, "Recent Improvements to the ITER Neutral Beam System Design," Fusion Engineering and Design, Vol. 87, No. 11, 2012, pp. 1805-1815.

[3] D. Ciric, D. P. D. Brown, C. D. Challis, B. Chuilon, S. J. Cox, B. Crowley, I. E. Day, D. C. Edwards, G. Evison, L. J. Hackett, S. Hotchin, Z. Hudson, I. Jenkins, T. T. C. Jones, R. King, M. Kovari, D. Martin, J. Milnes, A. Parkin, A. Li Puma, M. Shannon, A. Stevens, D. Stork, E. Surrey, C. Waldon, R. Warren, D. Wilson, D. Young and I. D. Young, "Overview of the JET Neutral Beam Enhancement Project," Fusion Engineering and Design, Vol. 82, No. 5-14, 2007, pp. 610-618. doi:10.1016/j.fusengdes.2007.07.046

[4] H. W. Kugel, G. M. Gammel, L. R. Grisham, R. Kaita, J. H. Camperschroer, R. A. Langley, C. W. Magee, S. S. Medley, T. J. Murphy, A. L. Roquemore and M. D. Williams, "Measurements of Neutral Beam Species, Impurities, Spatial Divergence, Energy Dispersion, Pressure, and Reionization Using the TFTR U.S. Common Long Pulse Ion Source," Review of Scientific Instruments, Vol. 60, No. 1, 1989, pp. 37-52. doi:10.1063/1.1140578

[5] K. H. Burrel, "Inject $2 \mathrm{MW}$ of Neutral Beam Power in the Counter Direction on DIII-D and Begin Physics Experiments," GA-C25590, General Atomics, San Diego, 2006.

[6] Y. Ikeda, the NBI Heating Group and NCT Design Team, "Progress of Neutral Beam Injection System on JT-60U for Long Pulse Operation," Journal of the Korean Physical Society, Vol. 49, No. 96, 2006, pp. S43-S47.

[7] Y. S. Bae, Y. M. Park, J. S. Kim, W. S. Han, S. W. Kwak, Y. B. Chang, H. T. Park, N. H. Song, H. L. Yang, S. W. Yoon, Y. M. Jeon, S. H. Hahn, S. G. Lee, W. H. Ko, A. C. England, W. C. Kim, Y. K. Oh, J. G. Kwak, M. Kwon, D. 
H. Chang, S. H. Jeong, T. S. Kim, B. H. Oh, J. T. Jin, S. R. In, K. W. Lee, D. S. Chang, K. Watanabe, M. Dairaku, H. Tobari, M. Kashiwagi, M. Hanada, T. Inoue, Y. Ikeda, M. Kawai, M. Komata, K. Mogaki, K. Usui, T. Yamamoto, M. Matsuoka, K. Nagaoka and L. Grisham, "Comissioning of the First KSTAR Neutral Beam Injection System and Beam Experiments," Fusion Engineering and Design, Vol. 87, No. 9, 2012, pp. 1597-1610. doi:10.1016/j.fusengdes.2012.05.011

[8] C. D. Hu, L. Z. Liang, Y. L. Xie, J. L. Wei, Y. H. Xie, J. Li, Z. M. Liu, S. Liu, C. C. Jiang, P. Sheng and Y. J. Xu, "Design of Neutral Beam-Line of EAST," Plasma Science and Technology, Vol. 13, No. 5, 2011, pp. 541-545. doi:10.1088/1009-0630/13/5/06

[9] C. D. Hu and NBI Team, "Conceptual Design of Neutral Beam Injection System for EAST," Plasma Science and Technology, Vol. 14, No. 6, 2012, pp. 567-572. doi:10.1088/1009-0630/14/6/30

[10] C. D. Hu, Y. H. Xie, S. Liu, Y. L. Xie, C. C. Jiang, S. H. Song, J. Li and Z. M. Liu, "First Plasma of Megawatt High Current Ion Source for Neutral Beam Injector of the Experimental Advanced Superconducting Tokamak on the Test Bed," The Review of Scientific Instruments, Vol. 82, No. 2, 2011, Article ID: 023303.

[11] C. D. Hu, Y. L. Xie and NBI Team, "The Development of a Megawatt-Level High Current Ion Source," Plasma Science and Technology, Vol. 14, No. 1, 2012, pp. 75-77. doi:10.1088/1009-0630/14/1/16

[12] Y. J. Xu, C. D. Hu, S. Liu, Y. H. Xie, L. Z. Liang and C. C. Jiang, "Preliminary Experimental Study of Ion Beam Extraction of EAST Neutral Beam Injector," Chinese
Physics Letters, Vol. 29, No. 3, 2012, Article ID: 035201.

[13] W. B. Kunkel, "Giant Sources of Neutral-Beam Injectors for Fusion (Invited)," Review of Scientific Instruments, Vol. 61, No. 1, 1990, pp. 354-359. doi:10.1063/1.1141292

[14] R. Hong and H. K. Chiu, "Effects of Operating Parameters on the Beam Species of DIII-D Neutral Beam Ion Sources," 19th Symposium on Fusion Engineering, Atlantic City, 21-25 January 2002, pp. 40-43.

[15] R. Becker and W. B. Herrannsfeldt, "IGUN-A Program for the Simulation of Positive Ion Extraction Including Magnetic Fields," Review of Scientific Instruments, Vol. 63, No. 4, 1992, pp. 2756-2758. doi:10.1063/1.1142795

[16] J. Kim, D. H. Chang, D. S. Chang, S. R. In, S. H. Jeong, J. T. Jin, K. S. Jung, B. Y. Kim, T. S. Kim, K. W. Lee, B. H. Oh, C. S. Seo, M. S. Seo, W. S. Song and B. J. Yoon, "An Ion Optics Study for KSTAR Neutral Beam Injector Development," The Review of Scientific Instruments, Vol. 79, No. 2, 2008, Article ID: 02C104.

[17] T.-S. Kim, S. H. Jeong, D.-H. Chang, S.-R. In, B.-H. Oh, D.-S. Chang, J.-T. Jin, C. S. Seo, K.-W. Lee, W.-S. Song and J.-C. Kim, "Beam Characteristics Study for the KSTAR Neutral Beam Long Pulse Ion Source," Current Applied Physics, Vol. 11, No. 5, 2011, pp. S145-S148. doi:10.1016/j.cap.2011.04.022

[18] R. M. Hong, B. G. Scoville, J. L. Busath, R. W. Callis, H. K. Chiu, H. J. Grunloh, C. Hu and M. G. Madruga, "Performance of a DIII-D Neutral Beam Ion Source with a New Accelerator Grid," 21st IEEE/NPS Symposium on Fusion Engineering, Knoxville, September 2005, pp. 1-3. 